\title{
Prevalence of anxiety and depression symptoms and their associated factors in mild COPD patients from community settings, Shanghai, China: a cross-sectional study
}

Tian Xiao ${ }^{1 \dagger}$, Hua Qiu ${ }^{2+}$, Yue Chen ${ }^{3}$, Xianfeng Zhou ${ }^{2}$, Kang Wu ${ }^{2}$ Xiaonan Ruan ${ }^{2}$, Na Wang $^{1 *}$ and Chaowei Fu ${ }^{1 *}$ (i)

\begin{abstract}
Background: Chronic obstructive pulmonary disease (COPD) is a serious disease frequently accompanied by anxiety and depression. Few studies have focused on anxiety and depression for mild COPD patients in China. This study aimed to assess the prevalence and associated factors for anxiety and depression among patients with mild COPD in urban communities.

Methods: A cross-sectional survey of 275 mild COPD patients was conducted in 6 communities randomly sampled from Pudong New Area of Shanghai, China, in 2016. Data on socioeconomic factors and health conditions were acquired through a face-to-face interview as well as a physical examination. The Hospital Anxiety and Depression Scale (HAD) and EQ-5D visual analogue (EQ-5D vas) were applied to evaluate their mental health and quality of life, respectively. Logistic regression model was used to estimate adjusted odds ratios (aORs) and their $95 \%$ confidential intervals (Cl) for risk factors associated with anxiety or depression.

Results: Among 275 subjects, 8.1\% had anxiety and 13.4\% had depression. Logistic regression analysis indicated that female patients were more likely to suffer from anxiety than male patients (aOR=6.41, 95\% Cl:1.73-23.80). Poor health status (EQ-5D vas score $<70$ ) was significantly associated with increased risks of anxiety (aOR $=5.99,95 \%$ Cl: 2. 13-16.82) and depression (aOR $=2.67,95 \% \mathrm{Cl}: 1.29-5.52)$.

Conclusions: There were increased risks of anxiety and depression in mild COPD patients living in urban communities. Female sex and poor health status were significantly correlated to anxiety or depression. More interventions should be developed to reduce the risks of anxiety and depression at the early stage of COPD.
\end{abstract}

Keywords: Depression, Anxiety, Quality of life, COPD, Mild

\section{Background}

Chronic obstructive pulmonary disease (COPD) was the fifth leading cause of mortality globally in 2011, and was expected to be the third leading cause by 2030 [1]. In 2010, the total cost of COPD was 50 billion US dollars and the average cost per patient

\footnotetext{
* Correspondence: fcw@fudan.edu.cn; na.wang@fudan.edu.cn

${ }^{\dagger}$ Equal contributors

${ }^{1}$ Department of Epidemiology, School of Public Health; Key Laboratory of Public Health Safety; Pudong Institute of Prevention Medicine, Fudan University, Shanghai 200032, China

Full list of author information is available at the end of the article
}

was over 4000 US dollars in the US, while they were respectively 36.9 billion and 2259 US dollars in China [2-6].

Patients of COPD are at a considerable risk of suffering from symptoms of depression and anxiety [7]. The prevalence of anxiety symptoms varied from 30 to $90 \%$, and that of depressive symptoms ranged from 13 to $70 \%$ among COPD patients (mostly inpatients) [8-13]. Previous studies indicated that anxiety and depressive symptoms in COPD patients were correlated with various factors including age, gender, 
severity of COPD, general health status, smoking, physical endurance and social performance [14-18]. These studies were mainly conducted among inpatients who had severe COPD, and few of them focused on the prevalences of depression and anxiety and their influencing factors among mild COPD patients in community settings [8-19]. The aim of this study was to estimate the prevalences of anxiety and depression among mild COPD patients living in urban Chinese communities and their associated factors.

\section{Methods}

\section{Study site and population}

A cross-sectional study was carried out in Pudong New Area of Shanghai, China, from June to August in 2016. A register system including data of diagnosed COPD patients from all secondary and tertiary hospitals was created in 2014. Six out of 46 communities were selected randomly to recruit patient with mild COPD. At the enrollment, spirometry function test was implemented on each patient to verify their COPD severity. Inclusion criteria were as follows: 1) a person was previously diagnosed as mild COPD according to the Global Initiative for Chronic Obstructive Lung Disease (GOLD) (forced expiratory volume in one second of percent predicted (FEV1\% predicted) $\geq 80 \%$, the ratio of FEV1 to forced vital capacity $(\mathrm{FVC})<0.7)[20]$; 2) a person provided informed consent and medical records were available; and 3) a person was a local resident aged 40 to 70 years and was capable of participating in the study by themselves. Patients with serious or unstable disease(s) (such as cardiovascular, neurological and musculoskeletal diseases) or inpatients were excluded. Patients with cognitive impairment and mobility limitation were excluded as well. Among 300 patients who participated in the study, 275 (91.7\%) met all the criteria and were included in this analysis.

\section{Data collection and quality control}

All information was collected by using a structured questionnaire and a physical examination. Demographic information included age, alcohol drinking history (Yes/No), smoking history (Yes/No), years of education $(<9$ years $/ \geq 9$ years $)$, monthly household income $(<3000 \mathrm{RMB} / \geq 3000 \mathrm{RMB})$, and regular exercise (Yes/No). Clinical information collected included disease duration, regular use of COPD medications in the past 12 months (Yes/No), exacerbation in the past 12 months (Yes/No) and comorbid conditions (hypertension, diabetes, kidney disease, stroke, cardiovascular diseases or others).
All field investigators received specific trainings in questionnaire interviewing, data recording and specific medical testing (scale assessment and spirometry function test) before the study was conducted. Questionnaire data were double-checked for its accuracy and completeness.

\section{Measurements of anxiety and depression symptoms as outcome variables}

The Hospital Anxiety and Depression Score (HAD) is a concise and commonly used questionnaire to assess the existence of depression and anxiety symptoms for COPD patients [21-25] (Additional file 1). The HAD is a self-administered questionnaire with two subscales (HAD-A for anxiety symptom and HAD-D for depression symptom) and each subscale contains seven items. Each item score ranges from 0 to 3, and the total score for each subscale ranges from 0 to 21 (0 manifests rare symptom, and 3 indicates apparent symptom) [21, 22]. Studies showed that HADs with $\geq 8$ points as cut-off points for anxiety and depression symptoms performed great sensitivity and specificity in Chinese patients $[19,26]$. Participants with a HAD score greater than 8 points were more likely to suffer from anxiety or depression, and a higher score implies more advanced severity of clinically anxious or depressed symptom [15, 18, 21, 27].

In the current study, we defined a patient with "anxiety" or "depression" as having a HAD-A or HAD-D score of 8 points or higher.

\section{Spirometry function test, physical examination and health status assessment}

Spirometry function test was performed at enrollment to acquire FEV1 and FVC values as well as FEV1\% predicted to determine COPD severity or stage according to the guideline for COPD [20]. Each patient inhaled $20 \mathrm{ml}$ salbutamol before pulmonary function testing was conducted and then complied with steps required for a spirometry function test. Final pulmonary function testing values were the average values of two satisfactory tests. Height and weight were measured to calculate body mass index (BMI, weight $(\mathrm{kg}) /$ height $\left.^{2}\left(\mathrm{~m}^{2}\right)\right)$. In addition, health status was assessed with EQ-5D visual analogue (EQ-5D $\mathrm{D}_{\text {vas }}$ ), which was considered to be a reliable and efficient tool for previous COPD studies [28-30]. Two previous studies used the visual analogue as a measure of quality of life in the association with depressive and anxious symptoms $[31,32]$. For the EQ- $5 D_{\text {vas }}$ test, each patient drew a horizontal line on a scale to represent their health status, ranging from 0 (worst imaginable health status) at the bottom to 100 (best imaginable health status) at the top. 


\section{Statistical analysis}

Data analysis was performed by using SAS 9.2 for Windows (SAS Institute, Inc., Cary, NC). Pearson Chi square test or Fisher exact test was used for comparisons of categorical variables. Student t-test or Wilcoxon test was applied for two-group comparisons of continuous variables with or without a normal distribution. Logistic regression analysis was used to estimate crude odds ratios (cORs) and adjusted OR $(\mathrm{aOR})$ as well as their 95\% confidential intervals (CI) for risk factors associated with anxiety or depression. The $p$ value of $<0.05$ was considered statistically significant.

\section{Results}

Basic characteristics of subjects

Among 275 patients, 134 (48.7\%) were male. The average age and BMI were $61.5 \pm 6.0$ years and $25.1 \pm$ $4.0\left(\mathrm{Kg} / \mathrm{m}^{2}\right)$, respectively. Nearly $40 \%$ of participants had a history of smoking, with a higher proportion of ever smoking in male patients than in female patients. Women had a longer average duration of COPD (13.2 years) and were more likely to have a comorbid condition (59.6\%), compared to men. There were no significant differences in EQ- $5 \mathrm{D}_{\text {vas }}$ scores, regular use of COPD medications, as well as exacerbation in the past 12 months between male and female patients (Table 1).

\section{Prevalences of anxiety and depression}

The overall prevalences of anxiety and depression were 7.6 and $13.1 \%$, respectively. Figure 1 shows the prevalences according to sex, smoking history and health status. An increased risk of anxiety was observed in female patients $(12.8 \%, P<0.001)$, smokers $(11.3 \%, P=0.008)$ and those with poor health status $\left(E Q-5 D_{\text {vas }}\right.$ score $\left.<70\right) \quad(15.6 \%, \quad P=0.0003)$. Patients with poor health status $\left(E Q-5 D_{\text {vas }}\right.$ score $\left.<70\right)(20.8 \%)$ were more likely to suffer from depression than those with better health status (8.9\%) $(P=0.005)$ (Fig. 2).

\section{Factors associated with anxiety and depression}

After adjustment for covariates, female patients were more likely to suffer from anxiety $(\mathrm{aOR}=6.41,95 \%$ CI: 1.73-23.80), and patients with poor health status (EQ-5D vas score $<70$ ) had a higher risk of anxiety $(\mathrm{aOR}=5.99,95 \%$ CI: 2.13-16.82) (Table 2). Similarly, poor health status was significantly associated with an increased risk of depression $(\mathrm{aOR}=2.67,95 \% \mathrm{CI}$ : 1 . 29-5.52) after important covariates were taken into account (Table 3).

\section{Discussion}

In this cross-sectional study, the prevalence was $7.6 \%$ for anxiety and $13.1 \%$ for depression (13.1\%) among mild COPD patients living in urban community. The prevalences for COPD patients were higher as compared with those for general populations [19, 33-35].

Table 1 Basic information among male and female patients with mild COPD

\begin{tabular}{|c|c|c|c|c|}
\hline Characteristics & Total & Male & Female & $P$ value \\
\hline Number $[n(\%)]$ & 275 & $134(48.7)$ & $141(51.3)$ & . \\
\hline Age, years [mean(SD)] & $61.5(6.0)$ & $62.1(5.4)$ & $60.9(6.5)$ & 0.113 \\
\hline BMI (kg/m2) [mean(SD)] & 25.1(4.0) & $24.7(3.9)$ & $25.5(4.2)$ & 0.074 \\
\hline Ever alcohol drinking $[n(\%)]$ & $54(19.6)$ & 49(36.6) & $5(3.5)$ & $<0.0001$ \\
\hline Ever smoking $[n(\%)]$ & $115(41.8)$ & $113(84.3)$ & $2(1.4)$ & $<0.0001$ \\
\hline Regular exercise $[n(\%)]$ & $98(35.6)$ & $48(35.8)$ & $50(35.5)$ & 0.95 \\
\hline \multicolumn{5}{|l|}{ Years of education $[n(\%)]$} \\
\hline$<9$ & $229(83.3)$ & $109(81.3)$ & $120(85.1)$ & \multirow[t]{2}{*}{0.403} \\
\hline$\geq 9$ & $46(16.7)$ & $25(18.7)$ & 21(14.9) & \\
\hline \multicolumn{5}{|l|}{ Monthly household income per capita/Yuan [n(\%)] } \\
\hline$<3000 /$ per month & $141(51.3)$ & $57(42.5)$ & $84(59.6)$ & \multirow[t]{2}{*}{0.005} \\
\hline$\geq 3000 /$ per month & $134(48.7)$ & $77(57.5)$ & $57(40.4)$ & \\
\hline Duration of COPD, year [mean(SD)] & $11.3(14.1)$ & $9.4(13.9)$ & $13.2(14.1)$ & 0.004 \\
\hline EQ-5Dvas score [mean(IQR)] & $70.6(14.3)$ & $70.1(14.6)$ & $71.0(14.1)$ & 0.322 \\
\hline Regular COPD medication use, in recent 12 months [n(\%)] & $97(35.3)$ & $48(35.8)$ & $49(34.8)$ & 0.853 \\
\hline Exacerbation, in recent 12 months [n(\%)] & $77(28.0)$ & $35(26.1)$ & $42(29.8)$ & 0.498 \\
\hline Comorbidity $[n(\%)]$ & $145(52.7)$ & $61(45.5)$ & $84(59.6)$ & 0.020 \\
\hline
\end{tabular}

Abbreviations: $B M I$ body mass index

For comparison, $X^{2}$ test used for binary variables, and Student's $t$ test or Wilcoxon non-parametric test employed for continuous variables; the bold $P$ values indicated the statistical significance 


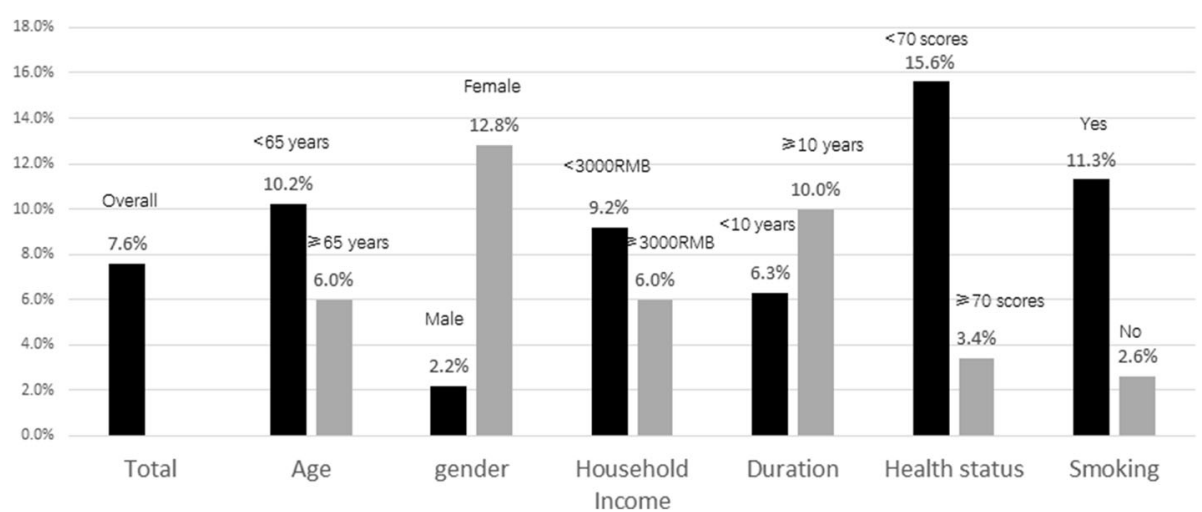

Fig. 1 Prevalence of anxiety symptoms among patients of mild COPD

Among the general adult population in China, the prevalences of anxiety and depression were 5.3 and 7 . $2 \%$, respectively, when assessed by the HADs scale, and were 5.6 and $6.1 \%$ when assessed by the Diagnostic and Statistical Manual of Mental Disorders fourth edition (DSM-IV) scale [19, 29]. Another Chinese cohort study of 0.5 million adults found that the prevalence of depressive symptoms was as low as $2.4 \%$, which was similar to the finding from a meta-analysis of 21 studies covering 11 provinces [30, 33]. The prevalence of anxiety varied from 10 to $100 \%$, while that of depression varied from 7 to $79 \%$ depending on the stage of COPD [34]. Most previous studies, which recruited COPD patients with moderate to extremely severe stages from hospitals, found inconsistent relationships between severity of COPD and mental health [19, 35-38]. Different instruments measuring anxiety and depression symptoms were used in different studies, which is one reason for study discrepancies $[39,40]$. In this study, only mild COPD patients from community settings were included. Our prevalence estimates were lower than those using the same scale of HAD (9.6 to $49 \%$ for anxiety and 22.8 to $52 \%$ for depression) [11, 38] except for one that included patients with mild COPD only [19].

For COPD patients, women were more likely to suffer from anxiety, and poor health status assessed by using EQ-5D was associated with increased risks of both anxiety and depression. A systematic review of 10 studies showed that women were significantly more likely to suffer from anxiety than men $(56 \%$ vs $35 \%, P=0.04)$, and similar sex disparity also existed in other studies [36, 40,41]. One possibility would be that female patients with COPD had a lower income level, a longer duration and more comorbid conditions, compared to male patients. However, sex difference remained significant after taking these factors into consideration. Similar finding for the relationships between health status and anxiety/depression were observed in other studies [14, 42, 43]. In one hand, those who have positive symptoms of anxiety or depression in general tend to report worse health status. In another hand, those with worse health status worry more about their conditions, which could worsen their anxiety or depression symptoms. A cross-sectional study provided no information on the direction of the associations. Therefore, cohort study

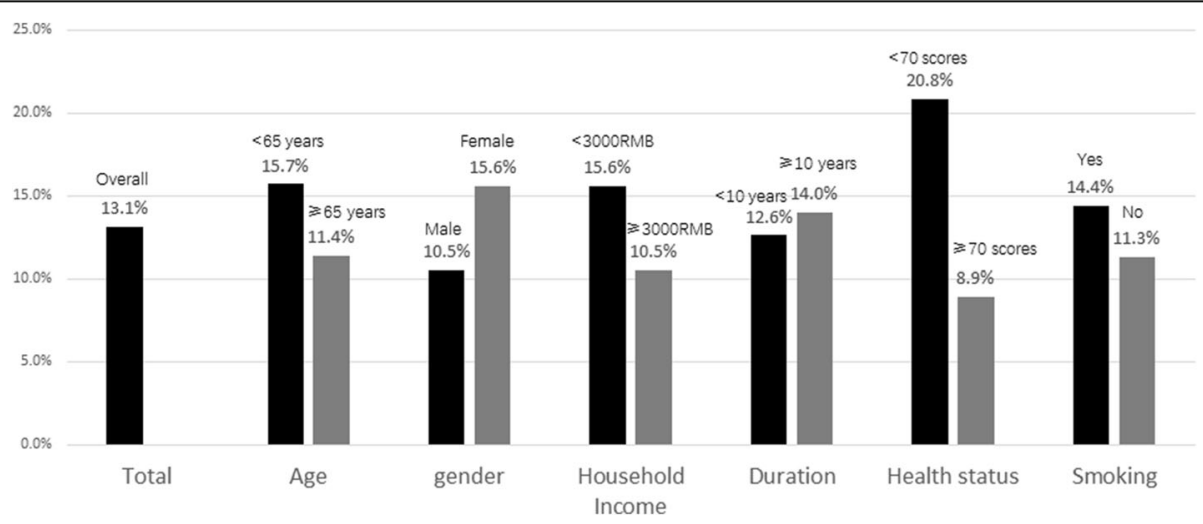

Fig. 2 Prevalence of depression symptoms among patients of mild COPD 
Table 2 Possible factors associated with anxiety symptoms among mild COPD patients

\begin{tabular}{|c|c|c|}
\hline Characteristics & $\mathrm{cOR}(95 \% \mathrm{Cl})^{\mathrm{a}}$ & $\mathrm{aOR}(95 \% \mathrm{Cl})^{\mathrm{b}}$ \\
\hline \multicolumn{3}{|l|}{ Gender } \\
\hline Male & 1.00 & 1.00 \\
\hline Female & $6.39(1.84 \sim 22.23)$ & $6.41(1.73 \sim 23.79)$ \\
\hline \multicolumn{3}{|l|}{ Age, years } \\
\hline$<65$ & 1.00 & 1.00 \\
\hline$\geq 65$ & $0.56(0.23 \sim 1.37)$ & $0.58(0.21 \sim 1.55)$ \\
\hline \multicolumn{3}{|c|}{ Household income per capita/Yuan } \\
\hline$<3000 /$ per month & 1.00 & 1.00 \\
\hline$\geq 3000 /$ per month & $0.86(0.63 \sim 1.16)$ & $1.04(0.74 \sim 1.46)$ \\
\hline \multicolumn{3}{|l|}{ Duration, years } \\
\hline$<10$ & 1.00 & 1.00 \\
\hline$\geq 10$ & $1.66(0.68 \sim 4.05)$ & $1.21(0.45 \sim 3.19)$ \\
\hline \multicolumn{3}{|l|}{ EQ-5Dvas score } \\
\hline$\geq 70$ & 1.00 & 1.00 \\
\hline$<70$ & $5.34(1.20 \sim 14.27)$ & $5.99(2.13 \sim 16.82)$ \\
\hline \multicolumn{3}{|l|}{ Comorbidities } \\
\hline No & 1.00 & 1.00 \\
\hline Yes & $0.98(0.40 \sim 2.40)$ & $0.90(0.33 \sim 2.43)$ \\
\hline
\end{tabular}

Abbreviations: $c O R$ crude odds ratio, aOR adjusted odds ratio

${ }^{a}$ Data represents univariate association as determined by logistic regression model

b Variable included in the multivariate logistic regression model: gender, age, monthly household per capita, disease duration, EQ-5Dvas score and comorbidity; the bold OR $(95 \% \mathrm{Cl})$ indicated the statistical relationship

design is required to further explore the nature of these associations.

There are strengths and limitations in this study. This study was conducted in urban communities and all invited subjects participated in the study. All subjects included in the study were confirmed to be at the mild stage of COPD based on a free post-bronchodilator pulmonary function test. However, a cross-sectional study design provided no evidence for causal associations between risk factors and presence of psychological symptoms. Since severe COPD cases were not included in this study and we could not assess the overall occurrences of anxiety and depression for COPD. In addition, the exclusion of any inpatients might result in an underestimation of the prevalences of anxiety and depression in mild COPD patients.

\section{Conclusions}

In conclusion, anxiety and depression were common in patients with mild COPD living in urban communities and mental health care services should be provided to these patients. Female sex and poor health status were significantly correlated to anxiety and depression
Table 3 Possible factors associated with depression symptoms among COPD patients

\begin{tabular}{|c|c|c|}
\hline Characteristics & $\operatorname{cOR}(95 \% \mathrm{Cl})^{\mathrm{a}}$ & $\mathrm{aOR}(95 \% \mathrm{Cl})^{\mathrm{b}}$ \\
\hline \multicolumn{3}{|l|}{ Gender } \\
\hline Male & 1.00 & 1.00 \\
\hline Female & $1.58(0.77 \sim 3.24)$ & 1.48(0.69 3.19) \\
\hline \multicolumn{3}{|l|}{ Age, years } \\
\hline$<65$ & 1.00 & 1.00 \\
\hline$\geq 65$ & $0.69(0.34 \sim 1.39)$ & $0.68(0.32 \sim 1.41)$ \\
\hline \multicolumn{3}{|c|}{ Household income per capita/Yuan } \\
\hline$<3000 /$ per month & 1.00 & 1.00 \\
\hline$\geq 3000 /$ per month & 0.86(0.68 1.09) & $0.91(0.71 \sim 1.17)$ \\
\hline \multicolumn{3}{|l|}{ Duration, year } \\
\hline$<10$ & 1.00 & 1.00 \\
\hline$\geq 10$ & $1.13(0.55 \sim 2.33)$ & $0.95(0.44 \sim 2.02)$ \\
\hline \multicolumn{3}{|l|}{ EQ-5Dvas score } \\
\hline$\geq 70$ & 1.00 & 1.00 \\
\hline$<70$ & $2.68(1.32 \sim 5.46)$ & $2.67(1.29 \sim 5.52)$ \\
\hline \multicolumn{3}{|l|}{ Comorbidities } \\
\hline No & 1.00 & 1.00 \\
\hline Yes & $0.88(0.44 \sim 1.78)$ & $0.89(0.43 \sim 1.86)$ \\
\hline
\end{tabular}

Abbreviations: $C O R$ crude odds ratio, $a O R$ adjusted odds ratio

${ }^{a}$ Data represents univariate association as determined by logistic regression model

${ }^{b}$ Variable included in the multivariate logistic regression model: gender, age, monthly household per capita, disease duration, EQ-5Dvas score and comorbidity; the bold OR $(95 \% \mathrm{Cl})$ indicated the statistical relationship

symptoms. More interventions should be developed to reduce the risks of anxiety and/or depression at the early stage of COPD in community settings.

\section{Additional file}

Additional file 1: The questionnaire for COPD patients in communities of Pudong District, Shanghai. The questionnaire covered on data of geographic, socioeconomic, lifestyle and occupational exposure factors, and COPD and comorbidities. (PDF $288 \mathrm{~kb}$ )

\section{Abbreviations}

Cl: Confidence interval; DSM-IV: Diagnostic and statistical manual fourth edition; HAD: The Hospital Anxiety and Depression Score; IQR: Interquartile range; OR: Odds ratio; SD: Standard deviation

\section{Acknowledgements}

All authors would like to give their thanks for the health professionals in community health centers and the individuals who participated in this study.

Funding

This work was founded by the Health Science Foundation of Shanghai (201540415), Shanghai 3-Year Public Health Action Plan (GWTD2015S04) and Shanghai Leading Academic Discipline Project of Public Health (15GWZK80101). The sponsors have no role in the study design, survey process, data analysis and manuscript preparation. 


\section{Availability of data and materials}

The datasets used and/or analyzed during the current study are available from the corresponding author on reasonable requests.

\section{Authors' contributions}

$\mathrm{CY}, \mathrm{RX}, \mathrm{QH}, \mathrm{WN}$, and FC contributed in study protocol and creation of questionnaire. $X \mathrm{~T}, \mathrm{QH}, \mathrm{ZX}, \mathrm{WK}$, and $\mathrm{RX}$ investigated and acquired information. $\mathrm{XT}, \mathrm{QH}, \mathrm{CY}, \mathrm{WN}$, and $\mathrm{FC}$ analyzed and interpreted the data and drafted and revised different sections of the manuscript. FC and WN are accountable for all aspects of the work in ensuring that questions related to the accuracy of any part of the manuscript are appropriate investigated and resolved. All authors read and approved the final manuscript.

\section{Authors' information}

Not applicable

\section{Ethics approval and consent to participate}

The ethic approval for this study was issued by the Institutional Review Board of the Fudan University School of Public Health. The nature and purpose of this study was illustrated and full confidentiality guaranteed. A written informed consent was obtained from all participants. They were permitted to withdraw from the study at any time without negative consequences.

\section{Consent for publication}

Not applicable.

\section{Competing interests}

The authors declare that they have no competing interests.

\section{Publisher's Note}

Springer Nature remains neutral with regard to jurisdictional claims in published maps and institutional affiliations.

\section{Author details}

'Department of Epidemiology, School of Public Health; Key Laboratory of Public Health Safety; Pudong Institute of Prevention Medicine, Fudan University, Shanghai 200032, China. ${ }^{2}$ Department of Chronic Disease, Pudong New Area Center for Disease Control and Prevention, Shanghai 200136, China. ${ }^{3}$ School of Epidemiology and Public Health, Faculty of Medicine, University of Ottawa, Ottawa, ON K1G 5Z3, Canada.

\section{Received: 31 October 2017 Accepted: 20 March 2018}

\section{Published online: 04 April 2018}

\section{References}

1. World Health Organization (WHO): Burden of COPD. Available from: http:// www.who.int/respiratory/copd/burden/en. Accessed 22 Mar 2018.

2. Soriano JB, Rodriguez-Roisin R. Chronic obstructive pulmonary disease overview: epidemiology, risk factors, and clinical presentation. Proc Am Thorac Soc. 2011;8(4):363-7.

3. Buist AS, McBurnie MA, Vollmer WM, Gillespie S, Burney P, Mannino DM, Menezes AM, Sullivan SD, Lee TA, Weiss KB, et al. International variation in the prevalence of COPD (the BOLD study): a population-based prevalence study. Lancet. 2007;370(9589):741-50.

4. Wu M, Zhao Q, Chen Y, Fu C, Xu B. Quality of life and its association with direct medical costs for COPD in urban China. Health Qual Life Outcomes. 2015;13:57.

5. Guarascio AJ, Ray SM, Finch CK, Self TH. The clinical and economic burden of chronic obstructive pulmonary disease in the USA. Clinicoecon Outcomes Res. 2013;5:235-45.

6. Chen X, Wang N, Chen Y, Xiao T, Fu C, Xu B. Costs of chronic obstructive pulmonary disease in urban areas of China: a cross-sectional study in four cities. Int J Chron Obstruct Pulmon Dis. 2016;11:2625-32.

7. Wagena EJ, van Amelsvoort LG, Kant I, Wouters EF. Chronic bronchitis, cigarette smoking, and the subsequent onset of depression and anxiety: results from a prospective population-based cohort study. Psychosom Med. 2005;67(4):656-60.

8. Bentsen SB, Miaskowski C, Rustoen T. Demographic and clinical characteristics associated with quality of life in patients with chronic obstructive pulmonary disease. Qual Life Res. 2014;23(3):991-8.
9. Di Marco F, Verga M, Reggente M, Maria CF, Santus P, Blasi F, Allegra L, Centanni S. Anxiety and depression in COPD patients: the roles of gender and disease severity. Respir Med. 2006;100(10):1767-74.

10. Eckerblad J, Todt K, Jakobsson P, Unosson M, Skargren E, Kentsson M, Theander K. Symptom burden in stable COPD patients with moderate or severe airflow limitation. Heart Lung. 2014;43(4):351-7.

11. Kunik ME, Roundy K, Veazey C, Souchek J, Richardson P, Wray NP, Stanley MA. Surprisingly high prevalence of anxiety and depression in chronic breathing disorders. Chest. 2005;127(4):1205-11.

12. Reinke LF, Slatore CG, Udris EM, Moss BR, Johnson EA, Au DH. The association of depression and preferences for life-sustaining treatments in veterans with chronic obstructive pulmonary disease. J Pain Symptom Manag. 2011;41(2):402-11.

13. Walke LM, Byers AL, Tinetti ME, Dubin JA, McCorkle R, Fried TR. Range and severity of symptoms over time among older adults with chronic obstructive pulmonary disease and heart failure. Arch Intern Med. 2007; 167(22):2503-8.

14. Cleland JA, Lee AJ, Hall S. Associations of depression and anxiety with gender, age, health-related quality of life and symptoms in primary care COPD patients. Fam Pract. 2007;24(3):217-23.

15. Gudmundsson G, Gislason T, Janson C, Lindberg E, Suppli UC, Brondum E, Nieminen MM, Aine T, Hallin R, Bakke P. Depression, anxiety and health status after hospitalisation for COPD: a multicentre study in the Nordic countries. Respir Med. 2006;100(1):87-93.

16. Dowson C, Laing R, Barraclough R, Town I, Mulder R, Norris K, Drennan C. The use of the hospital anxiety and depression scale (HADS) in patients with chronic obstructive pulmonary disease: a pilot study. N Z Med J. 2001; 114(1141):447-9.

17. Lewis KE, Annandale JA, Sykes RN, Hurlin C, Owen C, Harrison NK. Prevalence of anxiety and depression in patients with severe COPD: similar high levels with and without LTOT. COPD. 2007;4(4):305-12.

18. Ng TP, Niti M, Tan WC, Cao Z, Ong KC, Eng P. Depressive symptoms and chronic obstructive pulmonary disease: effect on mortality, hospital readmission, symptom burden, functional status, and quality of life. Arch Intern Med. 2007;167(1):60-7.

19. Lou P, Zhu Y, Chen P, Zhang P, Yu J, Zhang N, Chen N, Zhang L, Wu H Zhao J. Prevalence and correlations with depression, anxiety, and other features in outpatients with chronic obstructive pulmonary disease in China: a cross-sectional case control study. BMC Pulm Med. 2012;12:53.

20. Global Initiative for Chronic Obstructive Lung Disease. Global strategy for the diagnosis, management, and prevention of chronic obstructive pulmonary disease. 2017. Available from: http://goldcopd.org/global-strategy-diagnosismanagement-prevention-copd-2016. Accessed 22 Mar 2018.

21. Zigmond AS, Snaith RP. The hospital anxiety and depression scale. Acta Psychiatr Scand. 1983;67(6):361-70.

22. Bjelland I, Dahl AA, Haug TT, Neckelmann D. The validity of the hospital anxiety and depression scale. An updated literature review. J Psychosom Res. 2002;52(2):69-77.

23. McKenzie DK, Frith PA, Burdon JG, Town GI. The COPDX plan: Australian and New Zealand guidelines for the management of chronic obstructive pulmonary disease 2003. Med J Aust. 2003;178(Suppl):S7-S39.

24. Coventry PA, Bower P, Keyworth C, Kenning C, Knopp J, Garrett C, Hind D, Malpass $A$, Dickens $C$. The effect of complex interventions on depression and anxiety in chronic obstructive pulmonary disease: systematic review and meta-analysis. PLoS One. 2013;8(4):e60532.

25. Maurer J, Rebbapragada V, Borson S, Goldstein R, Kunik ME, Yohannes AM, Hanania NA. Anxiety and depression in COPD: current understanding, unanswered questions, and research needs. Chest. 2008;134(4 Suppl):43S-56S.

26. Zhang Q, Liao J, Liao X, Wu X, Wan M, Wang C, Ma Q. Disease knowledge level is a noteworthy risk factor of anxiety and depression in patients with chronic obstructive pulmonary disease: a cross-sectional study. BMC Pulm Med. 2014;14:92

27. Janssen DJ, Spruit MA, Leue C, Gijsen C, Hameleers H, Schols JM, Wouters EF. Symptoms of anxiety and depression in COPD patients entering pulmonary rehabilitation. Chron Respir Dis. 2010;7(3):147-57.

28. Wacker ME, Jorres RA, Karch A, Wilke S, Heinrich J, Karrasch S, Koch A, Schulz H, Watz H, Leidl R, et al. Assessing health-related quality of life in COPD: comparing generic and disease-specific instruments with focus on comorbidities. BMC PULM MED. 2016;16(1):70.

29. Phillips MR, Zhang J, Shi Q, Song Z, Ding Z, Pang S, Li X, Zhang Y, Wang Z. Prevalence, treatment, and associated disability of mental disorders in four 
provinces in China during 2001-05: an epidemiological survey. Lancet. 2009; 373(9680):2041-53.

30. Chen Y, Bennett D, Clarke R, Guo Y, Yu C, Bian Z, Ma L, Huang Y, Sun Q, Zhang $\mathrm{N}$, et al. Patterns and correlates of major depression in Chinese adults: a cross-sectional study of 0.5 million men and women. Psychol Med. 2017:47(5):958-70

31. Racic M, Todorovic R, Ivkovic N, Masic S, Joksimovic B, Kulic M. Selfperceived stress in relation to anxiety, depression and health-related quality of life among health professions students: a cross-sectional study from Bosnia and Herzegovina. Zdr Varst. 2017;56(4):251-9.

32. El FA, Bentata Y, Ada N, Oneib B. Depression and anxiety disorders in chronic hemodialysis patients and their quality of life: a cross-sectional study about 106 cases in the northeast of Morocco. Saudi J Kidney Dis Transpl. 2017;28(2):341-8.

33. Guo X, Meng Z, Huang G, Fan J, Zhou W, Ling W, Jiang J, Long J, Su L. Meta-analysis of the prevalence of anxiety disorders in mainland China from 2000 to 2015. Sci Rep. 2016;6:28033.

34. Andenaes R. Psychological characteristics of patients with chronic obstructive pulmonary disease: a review. J Psychosom Res. 2005;59(6):427-8.

35. Balcells E, Gea J, Ferrer J, Serra I, Orozco-Levi M, de Batlle J, Rodriguez E, Benet $\mathrm{M}$, Donaire-Gonzalez $\mathrm{D}$, Anto JM, et al. Factors affecting the relationship between psychological status and quality of life in COPD patients. Health Qual Life Outcomes. 2010;8:108.

36. Kim KU, Park HK, Jung HY, Ahn JJ, Moon E, Kim YS, Lee MK, Lee H. Association of depression with disease severity in patients with chronic obstructive pulmonary disease. Lung. 2014;192(2):243-9.

37. Iguchi A, Senjyu H, Hayashi Y, Kanada R, Iwai S, Honda S, Kitagawa C, Ozawa $\mathrm{H}$, Rikitomi N. Relationship between depression in patients with COPD and the percent of predicted FEV(1), BODE index, and health-related quality of life. Respir Care. 2013;58(2):334-9.

38. Eisner MD, Blanc PD, Yelin EH, Katz PP, Sanchez G, Iribarren C, Omachi TA. Influence of anxiety on health outcomes in COPD. Thorax. 2010;65(3):229-34.

39. Matte DL, Pizzichini MM, Hoepers AT, Diaz AP, Karloh M, Dias M, Pizzichini E. Prevalence of depression in COPD: a systematic review and meta-analysis of controlled studies. Respir Med. 2016;117:154-61.

40. Willgoss TG, Yohannes AM. Anxiety disorders in patients with COPD: a systematic review. Respir Care. 2013;58(5):858-66.

41. Laurin C, Lavoie KL, Bacon SL, Dupuis G, Lacoste G, Cartier A, Labrecque M. Sex differences in the prevalence of psychiatric disorders and psychological distress in patients with COPD. Chest. 2007;132(1):148-55.

42. Chavannes NH, Huibers MJ, Schermer TR, Hendriks A, van Weel C, Wouters EF, van Schayck CP. Associations of depressive symptoms with gender, body mass index and dyspnea in primary care COPD patients. Fam Pract. 2005;22(6):604-7.

43. Miravitlles M, Molina J, Quintano JA, Campuzano A, Perez J, Roncero C. Factors associated with depression and severe depression in patients with COPD. Respir Med. 2014;108(11):1615-25.

\section{Submit your next manuscript to BioMed Central and we will help you at every step:}

- We accept pre-submission inquiries

- Our selector tool helps you to find the most relevant journal

- We provide round the clock customer support

- Convenient online submission

- Thorough peer review

- Inclusion in PubMed and all major indexing services

- Maximum visibility for your research

Submit your manuscript at www.biomedcentral.com/submit 